\title{
Surgical treatment of recurrent aortic insufficiency after aortic valve replacement with the Starr-Edwards ball valve prosthesis
}

\author{
V I K ING OLOV B J ÖR K \\ From the Department of Thoracic and Cardiovascular Surgery, University Hospital, Uppsala, Sweden
}

\begin{abstract}
Experience with the Starr-Edwards ball valve prosthesis in 100 patients over a three-year period has so far given satisfactory results. In two patients in whom a recurrent aortic insufficiency was due to a bloodstream infection, the second operation consisted of removing the prosthesis and introducing a new ball valve prosthesis; both patients died. When the prosthesis was changed it was necessary to introduce a smaller one due to fibrosis around the aortic incision and the prosthesis. At operation it would have been technically possible to perform a local repair if the patient had not been infected.

In only three non-septic cases has a significant recurrent aortic insufficiency been encountered so far. To avoid the use of a smaller prosthesis a local repair was performed successfully. In a fourth patient a diastolic murmur was heard but aortography showed only a small anterior hole with only subvalvular leakage of no haemodynamic significance (grade I) and operation was not advised.
\end{abstract}

\section{CASE REPORTS}

CASE 1 A 19-year-old boy with a grade IV aortic insufficiency (left ventricle completely filled with contrast of the same density as in the aorta, after contrast injection in the aorta) had an enlarged heart of $540 \mathrm{ml} . / \mathrm{m}^{2}$ body surface. At operation on $16 \mathrm{Febru}$ ary 1961, three prolapsing aortic cusps were resected and replaced by three teflon cusps. The primary result was good and at follow-up one year later aortography showed only a slight subvalvular aortic leakage (aortic insufficiency grade I). Two years after operation the heart had decreased in size to $420 \mathrm{ml} . / \mathrm{m} .^{2}$ body surface and the blood pressure was $130 / 80 \mathrm{~mm}$. $\mathrm{Hg}$ with a short systolic and diastolic murmur. The patient could perform a normal workload test of 900 kilopondmeters/minute. Two years and two months after operation he developed symptoms of dyspnoea and bloodstained sputum, and a long diastolic murmur was audible over the whole precordium. The heart rapidly $\vec{c}$ dilated to $960 \mathrm{ml} . / \mathrm{m}^{2}$ body surface and the patient $\mathbb{D}$ went into failure with peripheral oedema which could not be relieved by medical treatment.

On 13 August 1963, when the patient was still in a bad condition and heart failure, three ruptured teflon cusps were excised and a no. 10 ball valve prosthesis $\vec{\theta}$ was introduced. All the tissues were oedematous and $\mathscr{\odot}$ bleeding was heavy with a spontaneous prothrombintime of less than 20 . The patient recovered but the blood culture was positive for Staphylococcus aureus. After intensive antibiotic treatment blood cultures be- $\overline{0}$ came negative, but a diastolic murmur could be heard in September 1963. The heart began slowly to dimin- $\mathbb{D}$

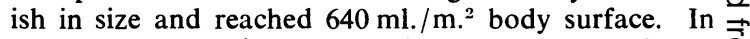
May 1964 thoracic aortography showed a grade IV aortic insufficiency (Fig. 1A).

The third operation was performed on 15 June 1964 . The sternotomy incision was reopened and, during a 54-minute perfusion with the disc oxygenator, the old aortotomy was opened. The aorta was occluded for $35 \mathrm{~min}$. and left-sided coronary perfusion was con- ֻ tinued for $28 \mathrm{~min}$. with a cannula mounted on a metal $\dot{0}$ handle. A $10 \mathrm{~mm}$. long slit-like hole was found anteriorly from the commissure between the noncoronary and the right coronary cusps to behind the right coronary artery (Fig. 1B). Five mattress sutures were placed through the collar of the prosthesis, $\frac{}{7}$ through the fibrotic base of the aorta, and then $D$ through a dacron patch. When the sutures had been tied the defect was occluded without tension. The N heart took over the circulation well. Before the repair or the pressure was $140 / 10 \mathrm{~mm}$. $\mathrm{Hg}$ in the left ventricle $N$ and $140 / 100 \mathrm{~mm}$. $\mathrm{Hg}$ in the brachial artery. After $\mathrm{N}$ repair it was $160 / 10 \mathrm{~mm}$. $\mathrm{Hg}$ in the left ventricle and $170 / 110 \mathrm{~mm}$. $\mathrm{Hg}$ in the brachial artery. The patient recovered and when he left hospital he had no diastolic $\stackrel{\circ}{\subset}$ murmur. Follow-up eight months later revealed a $\mathbb{\Phi}$ faint early diastolic murmur and a good general con-? dition. The heart had decreased to a normal size of $T$ $490 \mathrm{ml} . / \mathrm{m}^{2}$ body surface and a further aortography showed only a slight subvalvular aortic leakage (grade $\stackrel{\unrhd}{\mathbb{D}}$ I). The patient had a normal exercise tolerance of $\mathbb{D}$ 1,000 kilopondmeters/minute and was working full time. 


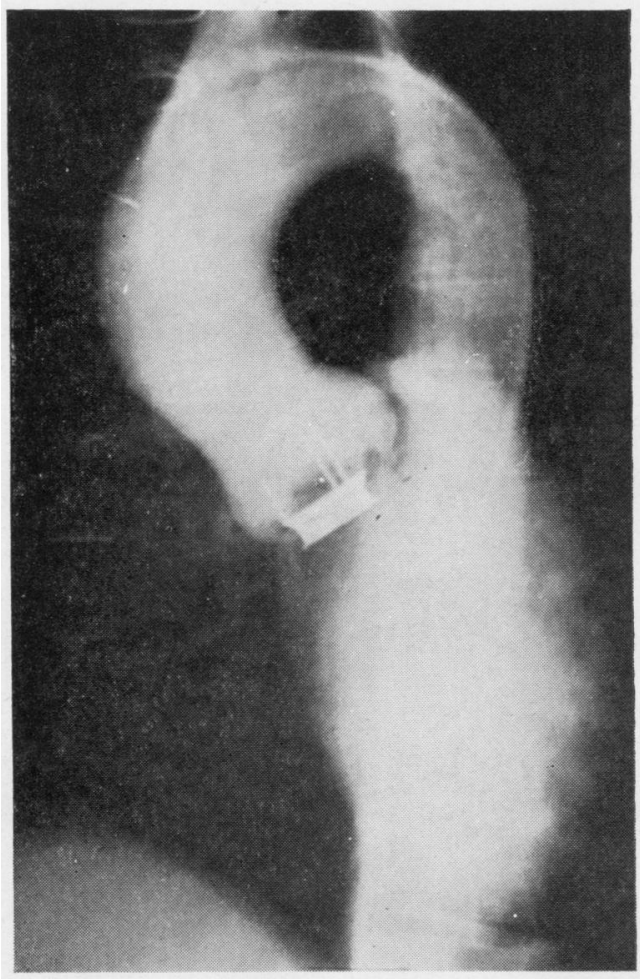

(A)

CASE 2 A 40-year-old man with a rheumatic history had had progressive aortic insufficiency for 10 years with successive dilatation of the heart, reaching a total volume of $1,710 \mathrm{ml}$., corresponding to $940 \mathrm{ml} . / \mathrm{m}^{2}$ body surface (Fig. 2A). Aortography showed a grade IV aortic insufficiency as well as a small sinus of Valsalva aneurysm. The diastolic volume of the left ventricle was $740 \mathrm{ml}$. and the minimal systolic volume $280 \mathrm{ml}$. On 4 February 1964, three prolapsing aortic cusps were excised and a no. 11 ball valve prosthesis was introduced. The prosthesis was slightly too big for the orifice and could not be pushed down into the left ventricle. The collar of the prosthesis was $1.5 \mathrm{~cm}$. below the coronary ostia. The prosthesis lay obliquely in the orifice because not all of its base could be pushed down. The patient needed respirator treatment through a tracheostomy for 10 days. In the immediate post-operative period a diastolic murmur was heard, but blood cultures were negative during intensive antibiotic treatment. Seven months after operation the patient had improved so much that the relative heart volume had decreased from $940 \mathrm{ml}$. to $640 \mathrm{ml} . / \mathrm{m}^{2}$ body surface (Fig. 2B). There was a diastolic murmur audible as well as a systolic murmur. Aortography showed a grade II to III aortic insuffciency (the left ventricle completely filled with contrast but density was never the same as in the aorta (Fig. $3)$ ). The blood pressure was $120 / 75 \mathrm{~mm}$. Hg. The

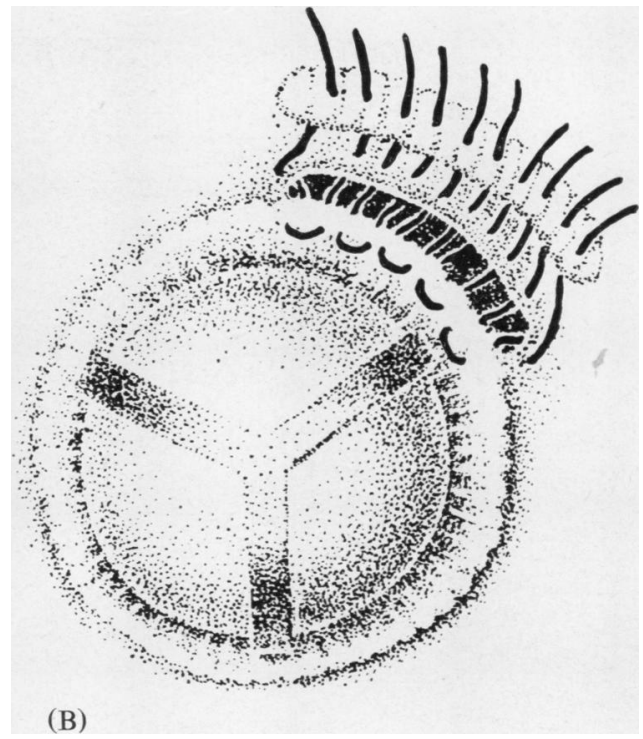

FIG. 1. Case 1. (A) Thoracic aortography shows a grade IV aortic insufficiency through a hole beside the prosthesis anteriorly. (B) Shows the hole beside the prosthesis anteriorly at the base of the right coronary cusp. Mattress sutures were placed through the collar of the prosthesis, through the fibrotic tissue of the aorta, and then through a dacron patch placed in the sinus of Valsalva inside the aorta.

patient tolerated a workload test of 900 kilopondmeters/minute. In spite of improvement in the patient's general condition and the decrease in heart size it was decided to operate again seven months after the first operation.

The median sternotomy was reopened and a 53minute perfusion with the disc oxygenator was carried out. The aorta was opened and in the commissure between the left and right coronary cusps there was a slit-like hole, $1 \mathrm{~cm}$. in diameter, beside the prosthesis where the sutures had cut out. There was, in addition, another small hole, $3 \mathrm{~mm}$. in diameter, at the base of the commissure between the right and the noncoronary cusps. Five mattress sutures were placed through the collar of the Starr-Edwards prosthesis, through the root of the aorta, and up through a dacron patch (Fig. 4). The aortotomy was closed after evacuation of the air, and the heart took over the circulation with a good blood pressure. Left coronary perfusion only had been used for $38 \mathrm{~min}$. through a cannula on a metal handle during the aortic occlusion, which lasted for 42 minutes. Pressure in the left ventricle before the correction was $200 / 55 \mathrm{~mm}$. $\mathrm{Hg}$ and in the brachial artery $140 / 70 \mathrm{~mm}$. $\mathrm{Hg}$; in other words, a systolic pressure gradient of $60 \mathrm{~mm}$. $\mathrm{Hg}$ in the presence of the aortic insufficiency. When the insufficiency had disappeared after the operation the left ventricular pressure was $110 / 15 \mathrm{~mm}$. $\mathrm{Hg}$ when the brachial artery 


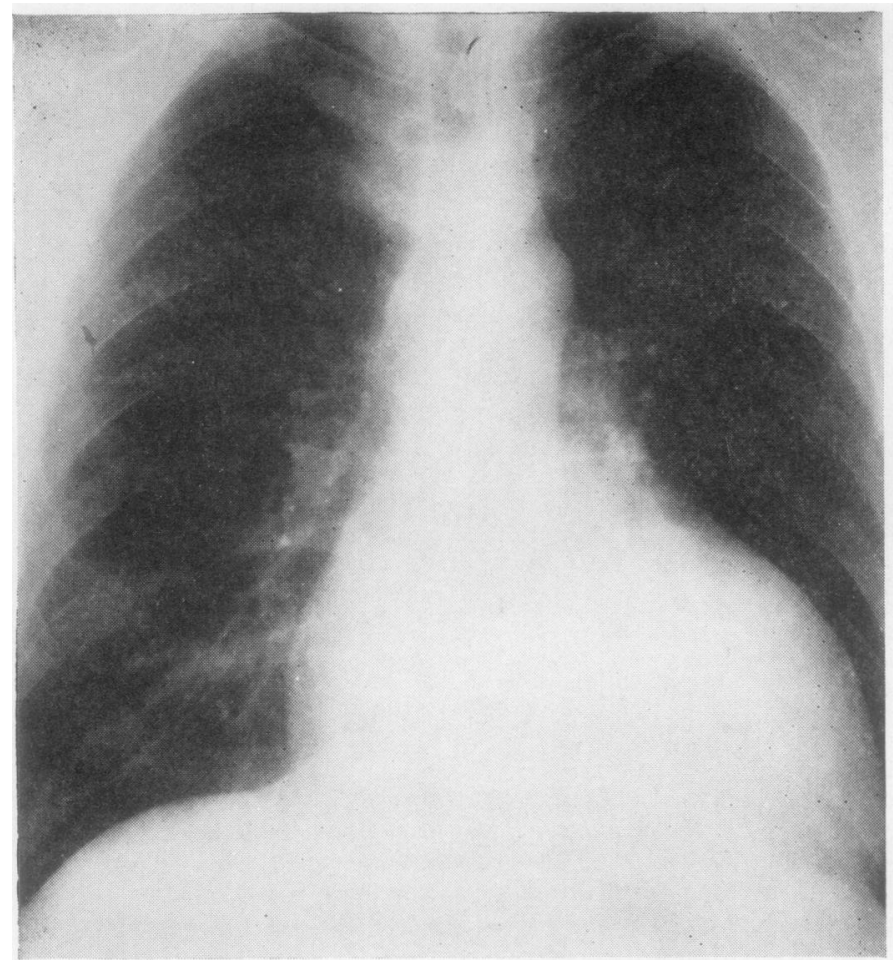

FIG. 2. Case 2. Chest radiographs show (A) a huge heart of $1,710 \mathrm{ml}$., corresponding to $940 \mathrm{ml} . / \mathrm{m}^{2}$ body surface; (B) a decrease of relative heart size from $940 \mathrm{ml}$. to $640 \mathrm{ml} . / \mathrm{m}^{2}$ body surface during the seven months after the introduction of $a$ ball valve prosthesis. 


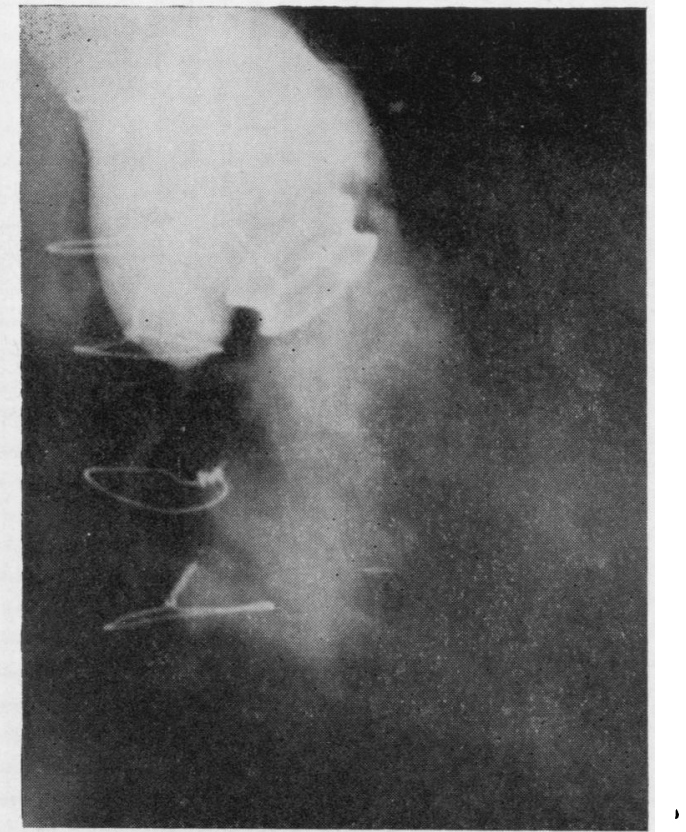

FIG. 3. Case 2. Aortography shows a grade II to III aortic insufficiency through a localized, slit-formed hole anterior to the ball valve prosthesis.

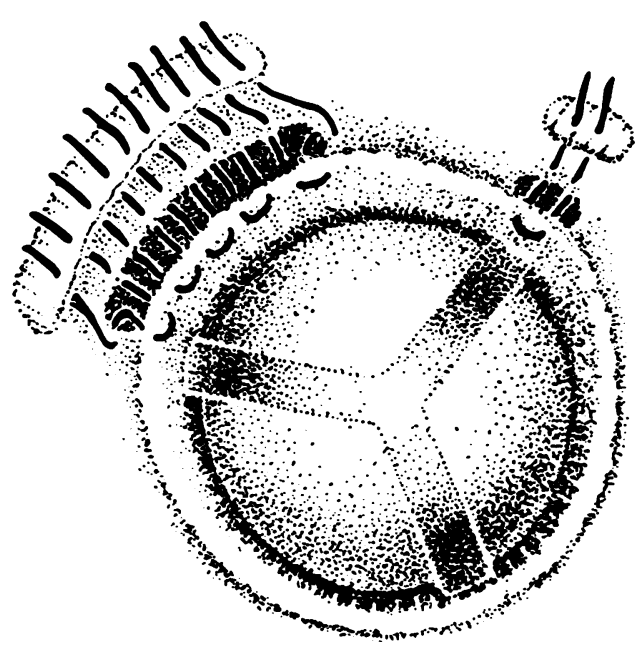

FIG. 4. Case 2. Shows the finding at operation with one slit-formed hole anteriorly (left) and another hole anteriorly (right). Mattress sutures were placed through the collar of the prosthesis, through the aorta, and in through a dacron patch placed on the inside of the aorta.

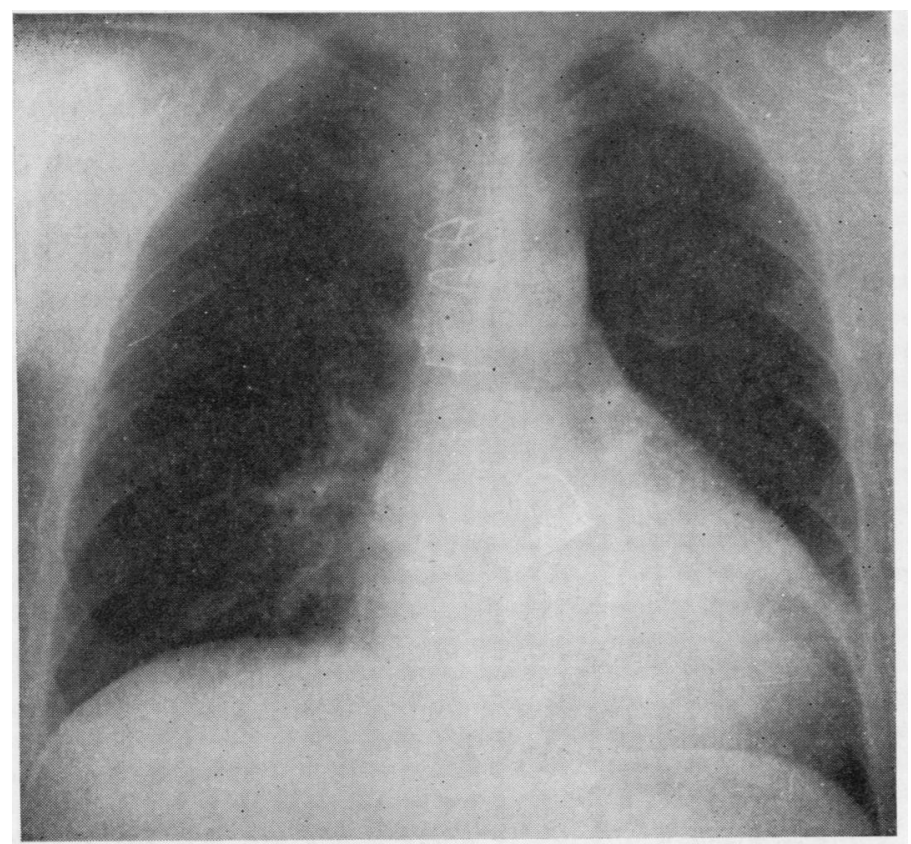

FIG. 5. Case 2. Chest radiograph shows a further decrease in heart size to $590 \mathrm{ml} . / \mathrm{m}^{2}$ body surface at the four-month follow-up after the second operation. 
pressure was $120 / 90 \mathrm{~mm}$. $\mathrm{Hg}$. The systolic pressure gradient had disappeared and there was a decrease in the end-diastolic pressure from the left ventricle. I submit that the operation must be considered to have been worth while in spite of the fact that improvement had already been obtained from the first operation. The patient made an uneventful recovery and left hospital in excellent condition and without signs of a diastolic murmur. Follow-up after four months showed a decrease in the heart size to $590 \mathrm{ml} . / \mathrm{m}^{2}{ }^{2}$ body surface (Fig. 5) and no diastolic murmur. The patient was working full time.

CASE 3 A 40-year-old man had experienced an endocarditis nine years earlier and had suffered from angina pectoris for eight years. The heart was of normal size. $430 \mathrm{ml} . / \mathrm{m}^{2}$ body surface. Loud systolic and diastolic murmurs were heard over the root of the aorta. Left heart catheterization showed a systolic pressure gradient of $85 \mathrm{~mm}$. $\mathrm{Hg}$ at rest over the aorta, and tomography demonstrated extensive calcifications. Thoracic aortography showed a grade IV aortic insufficiency. The left ventricle had good contractions. On 21 May 1963, the aortic ostium was excised. Due to the extensive calcifications hardly any rim was left anteriorly at the base of the valves. There were subvalvular calcifications below the right cusp, below the non-coronary cusp, and at the base of the anterior mitral leaflet. A no. 10 ball valve prosthesis was placed in position during a two-hour perfusion. The heart took over the circulation with good blood pressure. Pressu measurements on the table before correction showe in the left ventricle $190 / 10 \mathrm{~mm}$. $\mathrm{Hg}$. and in the brachia artery $140 / 80 \mathrm{~mm}$. Hg; after the correction, $105 \%$ $\mathrm{mm} . \mathrm{Hg}$ in the left ventricle and $110 / 70 \mathrm{~mm}$. $\mathrm{Hg}$ in the brachial artery. The patient made an uneventfot recovery and left hospital after four weeks in good condition and without a diastolic murmur. $\mathrm{He}$ was sent home with antibiotics and anticoagulants. he came from a foreign country he could not be for lowed up until 14 months had clapsed. Then a diastolis murmur was audible all over the heart. There was a haematocrit of 27 with a serum iron of $20 \mathrm{mg} . / 100 \mathrm{~m}$ ? The heart had enlarged to $610 \mathrm{ml} . / \mathrm{m}^{2}$ body surface Aortography showed grade IV insufficiency localizeg anteriorly beside the prosthesis (Fig. 6A). Cineradio graphy showed no abnormal twisting of the prosthesis: The patient could only perform 400 kilopondmeters minute.

A further operation was advised and performed $\overrightarrow{\mathbb{D}}$ months after the first operation. The median stern tomy was reopened, and during a 57-minute perfusiof the aorta was opened and a $2 \mathrm{~cm}$. long slit-like hoظ was found $1 \mathrm{~cm}$. on each side of the commissure b. tween the left and right coronary cusps. It was noticed that anteriorly, after resection of the calcific cusps, nf ridge was left. Seven sutures through the collar of the prosthesis were placed through the root of the
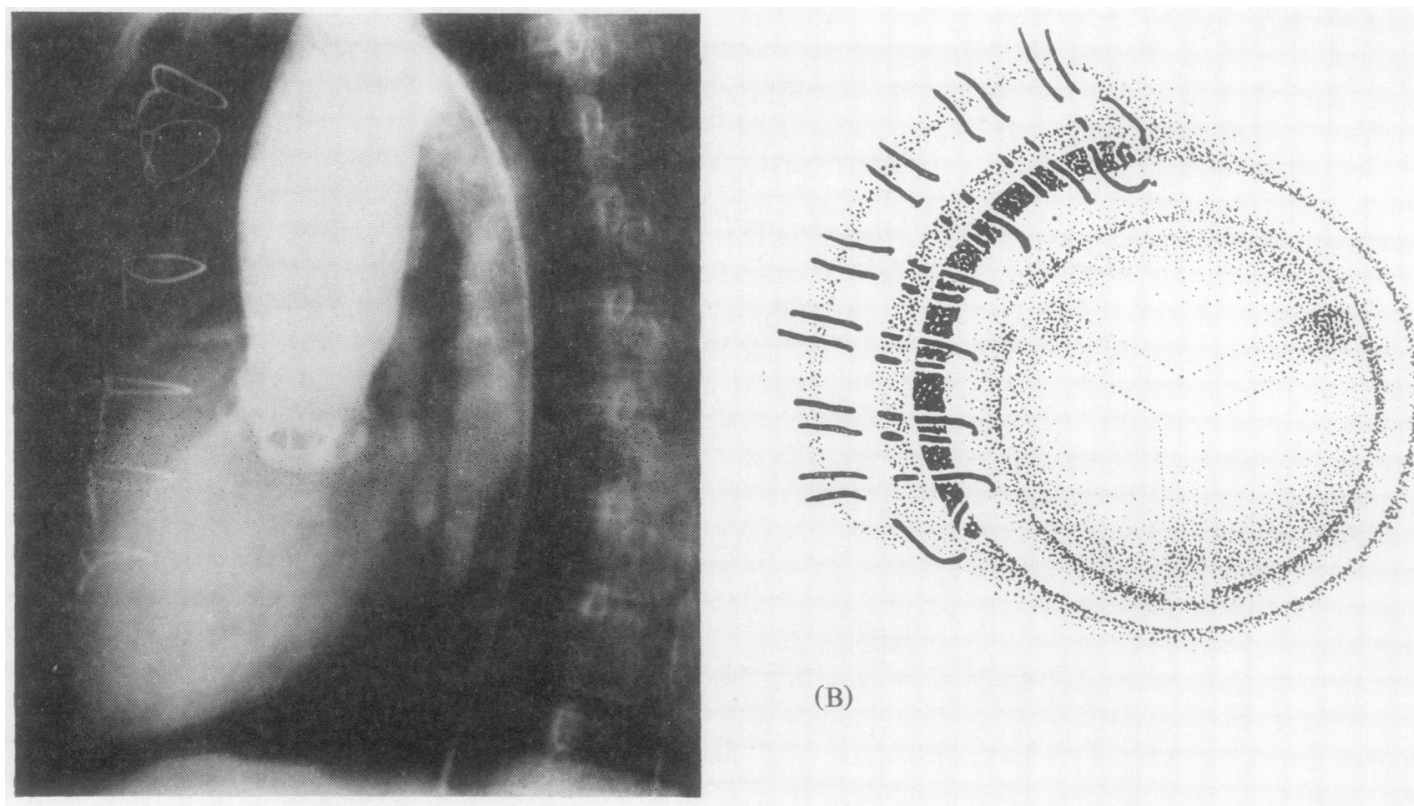

(A)

FIG. 6. Case 3. (A) Aortography shows a grade IV aortic insufficiency localized anteriorly beside the ball valve prosthesis. (B) Shows the $20 \mathrm{~mm}$. long slit-like hole found at operation anteriorly at the base of the right coronary cusp. Seven sutures approximated the collar of the prosthesis to the aorta. The sutures were buffered by a dacron patch on the inside of the aorta. 
aorta and through a patch of dacron, and, when tied, the aortic wall was approximated to the collar of the prosthesis (Fig. 6B).

During aortic occlusion, lasting 52 minutes, only left coronary artery perfusion, with a cannula on a metal handle, was used. The heart took over the circulation with a good blood pressure. Pressure measurement before correction showed in the left ventricle $180 / 30$ $\mathrm{mm}$. $\mathrm{Hg}$, in the brachial artery $160 / 60 \mathrm{~mm} . \mathrm{Hg}$, and after correction $165 / 10 \mathrm{~mm}$. $\mathrm{Hg}$ in the left ventricle and $160 / 90 \mathrm{~mm} . \mathrm{Hg}$ in the brachial artery. In other words, the insufficiency with the bigger stroke volume had caused a systolic gradient over the aortic orifice of $20 \mathrm{~mm}$. Hg. The patient recovered and the diastolic murmur disappeared. One month after the second operation the heart had decreased in size from $610 \mathrm{ml}$. to a normal $430 \mathrm{ml} . / \mathrm{m}^{2}$ body surface and the patient was in excellent condition without a diastolic murmur.

\section{DISCUSSION}

The weakest area in the normal aortic base seems to be anteriorly between the right and left coronary cusps. The connexion between the aortic wall and the ventricular septum, corresponding to the base of the aortic valves, contains only very little elastic tissue. It seems that this region at the commissure between the right and left coronary cusps is the weak area in the aortic root. In the six cases where an infection after introduction of a ball valve prosthesis caused a suture insufficiency, five had in addition a false aneurysm at the site of the suture insufficiency. This was always situated anteriorly. In one case, where the sutures holding the prosthesis had cut through for two-thirds of the circumference, the prosthesis was fixed only at the base of the non-coronary cusp. The area of the left and right coronary cusps should therefore be regarded as the weak area where it is essential to place the sutures close enough together and buffered by a teflon pearl to prevent their cutting through. It was during a second operation on two of these infected cases that it became obvious that a local repair would have been possible in the absence of a blood- stream infection. The cause of suture insufficiency is considered to have been infection in case 1; in case 2, too big a prosthesis was used. It was not possible to insert the prosthesis all the way down into the left ventricle; only part of the prosthesis would come below the coronary ostia. In the area of the non-coronary cusp, the prosthesis could not be inserted low enough. Therefore extra tension was placed on the sutures at the time of the insertion of the prosthesis. In both cases 1 and 2 a diastolic murmur had appeared before the patient left hospital. In case 1 it might be thought that the oedema found in all the tissues was a complicating factor. In the third case there was no rim left anteriorly when the calcific aortic rock had been removed. Therefore the sutures were actually placed in the muscle of the interventricular septum. They held for the first month and there was no diastolic murmur when the patient left hospital. A significant insufficiency was first found at the one-year follow-up. Significant insufficiency in the presence of a ball valve prosthesis causes a gradient due to the increased stroke volume through an already narrow orifice. This gradient disappeared after local repair and the end-diastolic pressure decreased at the end of the operation (see Table).

At the further operations on the infected cases it was found that, on account of fibrosis at the base of the prosthesis and in the aortic incision, it was necessary to use a smaller ball valve prosthesis at the second operation. Therefore a local repair is recommended at the second operation as it is a quicker and simpler procedure requiring a shorter perfusion time and it obviates the need to change to a smaller ball valve prosthesis. There does not seem to be any point in detaching the fibrous connexion in the intact area between the root of the aorta and the collar of the prosthesis in the absence of infection. I emphasize again that it is important to use a prosthesis that can be introduced into the left ventricle, and one that is not too large.

\section{T A B L E}

PRESSURE MEASUREMENTS DURING OPERATION BEFORE AND AFTER LOCAL REPAIR OF AORTIC INSUFFICIENCY THROUGH A HOLE AT THE SIDE OF A BALL VALVE PROSTHESIS

\begin{tabular}{|c|c|c|c|c|c|c|c|c|c|c|c|}
\hline \multirow{3}{*}{$\begin{array}{l}\text { Case } \\
\text { No. }\end{array}$} & \multirow{3}{*}{$\begin{array}{c}\text { Age } \\
\text { (yrs.) }\end{array}$} & \multirow{3}{*}{$\begin{array}{c}\text { Weight } \\
\text { (kg.) }\end{array}$} & \multirow{3}{*}{$\begin{array}{l}\text { B.S.A. } \\
\text { (sq. m.) }\end{array}$} & \multicolumn{2}{|c|}{ Time (min.) } & \multirow{3}{*}{$\begin{array}{c}\text { No. of } \\
\text { Aortic } \\
\text { Prosthesis }\end{array}$} & \multirow{3}{*}{$\begin{array}{c}\text { Length } \\
\text { of } \\
\text { Hole } \\
(\mathrm{mm} .)\end{array}$} & \multicolumn{4}{|c|}{ Pressures $(\mathrm{mm} . \mathbf{H g})$} \\
\hline & & & & & & & & \multicolumn{2}{|c|}{ Before } & \multicolumn{2}{|c|}{ After } \\
\hline & & & & $\begin{array}{c}\text { Per- } \\
\text { fusion }\end{array}$ & $\begin{array}{c}\text { Aortic } \\
\text { Occlusion }\end{array}$ & & & $\begin{array}{c}\text { Left } \\
\text { Ventricle }\end{array}$ & Aorta & $\begin{array}{c}\text { L eft } \\
\text { Ventricle }\end{array}$ & Aorta \\
\hline $\begin{array}{l}1 \\
2 \\
3\end{array}$ & $\begin{array}{l}19 \\
40 \\
40\end{array}$ & $\begin{array}{l}61 \\
65 \\
56\end{array}$ & $\begin{array}{l}1 \cdot 7 \\
1 \cdot 8 \\
1 \cdot 7\end{array}$ & $\begin{array}{l}54 \\
53 \\
57\end{array}$ & $\begin{array}{l}35 \\
42 \\
52\end{array}$ & $\begin{array}{l}10 \\
11 \\
10\end{array}$ & $\begin{array}{c}10 \\
10+3 \\
20\end{array}$ & $\begin{array}{l}140 / 10 \\
200 / 55 \\
180 / 30\end{array}$ & $\begin{array}{ll}140 & 100 \\
14070 \\
16060\end{array}$ & $\begin{array}{l}160 / 10 \\
110 / 15 \\
165 / 10\end{array}$ & $\begin{array}{l}170 / 110 \\
12090 \\
160 / 90\end{array}$ \\
\hline
\end{tabular}




\section{SUMMARY}

Recurrent aortic insufficiency after the insertion of a Starr-Edwards ball valve prosthesis can be adequately treated by a local repair in the absence of a bloodstream infection. A local repair is a shorter procedure and avoids an exchange to a smaller ball valve prosthesis. A local repair has given good results at the second operation in three patients. The possibility of performing a locat repair after recurrent insufficiency using the Star Edwards ball valve prosthesis is an advantage ove the use of a sutureless prosthesis.

\section{BIBLIOGRAPHY}

Björk, V. O. (1964). Aortic valve replacement. Thorax, 19, 369. Starr, A., Edwards, M. L., McCord, C. W., and Griswold, H. E (1963). Aortic replacement: clinical experience with a semirigo ball-valve prosthesis. Circulation, 27, 779. 